\title{
Innovative Mining Equipment: Key Factors for Successful Implementation
}

\author{
Bryan Boudreau-Trudel ${ }^{1}$, Sylvie Nadeau${ }^{1}$, Kazimierz Zaras ${ }^{2}$ \\ ${ }^{1}$ Department of Mechanical Engineering, École de Technologie Supérieure, Montréal, Canada \\ ${ }^{2}$ Department of Management, Université du Québec en Abitibi-Témiscamingue, Rouyn-Noranda, Canada \\ Email: bryan.trudel@uqat.ca, sylvie.nadeau@etsmtl.ca, kazimierz.zaras@uqat.ca
}

Received 9 March 2015; accepted 5 April 2015; published 8 April 2015

Copyright (C) 2015 by authors and Scientific Research Publishing Inc.

This work is licensed under the Creative Commons Attribution International License (CC BY). http://creativecommons.org/licenses/by/4.0/

(c) (i) Open Access

\begin{abstract}
With increasing social pressures over the past two decades, mining companies have become more concerned with occupational health and safety (OHS). This change in mentality has had an impact on the choice of new equipment introduced underground. Introduction of innovative mining equipment must now meet the double challenge of improving both productivity and OHS. However, innovative equipment does not by itself ensure success. The aim of this study is to identify the key factors that underlie successful introduction of new equipment in underground mines. We used a multi-attribute decision-aid tool, namely the dominance-based rough-set approach. Ten innovative equipment projects carried out in an underground mine in Quebec were analysed. The tool allowed simultaneous identification of the most relevant factors and critical thresholds thereof to establish levels of performance based on four indicators, namely cost per meter drilled, cost per hour of use, availability ratio and accident rate. Two factors were found most relevant to all four indicators of performance: the skill requirement and acceptance of the equipment by the operators. Seat quality was identified as a contributor to improving accident rate, while standardisation of the new equipment relative to the old contributed to productivity. Taking into consideration these key factors and their critical threshold values will help the directors of the participating mine to meet with success in terms of both productivity and OHS in future introduction of innovative equipment projects.
\end{abstract}

\section{Keywords}

Mining, Innovation, Equipment, Productivity, Occupational Health and Safety

\section{Introduction}

The mining industry evolves in an economic environment that undergoes continual change due to cycles of

How to cite this paper: Boudreau-Trudel, B., Nadeau, S. and Zaras, K. (2015) Innovative Mining Equipment: Key Factors for Successful Implementation. American Journal of Industrial and Business Management, 5, 161-171.

http://dx.doi.org/10.4236/ajibm.2015.54018 
fluctuating metal prices at the whims of international trading of securities. Compounding this pressure is competition from developing nations. These exogenous factors push mining companies to examine technologies as means of improving productivity [1]. However, unlike during the early days of this industry, productivity can no longer be the only factor taken into consideration when choosing new equipment [2]. The importance of occupational health and safety (OHS) is increasing for many mining companies, who now face mounting social pressures [3]. The choice of equipment must therefore meet the two-fold challenge of increasing productivity while improving OHS [4] [5].

However, the introduction of technological innovation does not guarantee that this challenge will be met with success. Several studies describe equipment upgrades that have gone awry. According to the Centre for Excellence in Mining Innovation (CEMI), progress in meters per day in Ontario mines actually dropped following the arrival of new electro-hydraulic devices and innovations in automation, from $15 \mathrm{~m}$ per day in 1980 to only $3.8 \mathrm{~m}$ per day in 2011 [6]. Studies also show that a large proportion of the accidents and deaths that have occurred in North American mining since the turn of the millennium are attributable to equipment misuse or failure [7]-[10].

These facts underscore the need for better understanding of the factors and conditions that lead to successful implementation of technological innovation in mining. Since the simple arrival of new equipment does not by itself guarantee improvement of productivity or OHS, what are the factors that make the difference? The present study is focused on this question and aims specifically to identify the key factors that contribute to the success of such initiatives.

\section{Methodology}

Management of innovation in mining is subject to the influence of several factors. We have identified nearly 20 of these in our review of the literature [11]. However, which of these are the most important, the most relevant to successful implementation, remains to be determined. To answer this question, we propose combining two decision-aid methods. Firstly, we used AXE-type classical multi-attribute analysis where:

A is a finite set of innovative equipment projects $a_{i}$ for $i=1,2, \ldots n$;

$\mathbf{X}$ is a set of attributes $X_{k}$ for $k=1,2, \ldots m$;

$\mathbf{E}$ is a set of evaluations of project $e\left[\left(a_{i}\right), k\right]$ for each project $a_{i}$ in terms of each attribute $X_{k}$.

This multi-attribute analysis thus consists of evaluating individually each of a set of projects in terms of the influence of each conditional attribute that could have an influence on success. Secondly, decisional attributes represented by performance indicators as used in the dominance-based rough set approach [12] [13] are added to the model to measure impact of implementation. We have chosen this artificial intelligence tool because it allows "if... then..." type decision rules to be deduced from examples. These rules identify the most relevant attributes and the critical thresholds thereof simultaneously to obtain the level of result with respect to a decisional attribute (performance indicator). To obtain these rules, we must first construct a decision table such as shown in Table 1.

In this decision table, the examples $\left(a_{1}, a_{2}, \ldots a_{n}\right)$ correspond to projects as identified in the AXE multi-attribute model. For our purposes, 10 innovative equipment projects in an underground mine in province of Quebec were selected with the approval of the company directors. These are described briefly in Section 3.

Each project was then evaluated in terms of the AXE conditional attributes $\left(\mathrm{X}_{1}, \ldots \mathrm{X}_{\mathrm{n}}\right)$. Conditional attributes are contextual factors (conditions under which the project was carried out) that could have an influence on the success of the project. The list of factors that were considered in this study and the range of rating of each are listed in Appendix ${ }^{1}$. To obtain the evaluations used for the ratings, we used semi-directed interviews. Eleven

Table 1. Decision table.

\begin{tabular}{ccccc}
\hline & $\mathbf{X}_{1}$ & $\ldots$ & $\mathbf{X}_{\mathbf{m}}$ & $\mathbf{D}$ \\
\hline $\mathrm{a}_{1}$ & $\mathrm{e}\left[\left(\mathrm{a}_{1}\right), 1\right]$ & $\ldots$ & $\mathrm{e}\left[\left(\mathrm{a}_{1}\right), \mathrm{m}\right]$ & $\mathrm{e}\left(\mathrm{a}_{1}\right)=\{1,2,3$ or 4$\}$ \\
$\mathrm{a}_{2}$ & $\mathrm{e}\left[\left(\mathrm{a}_{2}\right), 1\right]$ & $\ldots$ & $\mathrm{e}\left[\left(\mathrm{a}_{2}\right), \mathrm{m}\right]$ & $\mathrm{e}\left(\mathrm{a}_{2}\right)=\{1,2,3$ or 4$\}$ \\
$\ldots$ & $\ldots$ & $\ldots$ & $\ldots$ & $\ldots$ \\
$\mathrm{a}_{\mathrm{n}}$ & $\mathrm{e}\left[\left(\mathrm{a}_{\mathrm{n}}\right), 1\right]$ & $\ldots$ & $\mathrm{e}\left[\left(\mathrm{a}_{\mathrm{n}}\right), \mathrm{m}\right]$ & $\mathrm{e}\left(\mathrm{a}_{\mathrm{n}}\right)=\{1,2,3$ or 4$\}$ \\
\hline
\end{tabular}

${ }^{1}$ These are factors for which variation from one evaluation to the next is known to occur. Other factors such as training and user involvement in equipment design were considered, but were not found to vary. 
company employees at different levels in the hierarchy, from miner-operator to mine superintendent, were queried to obtain their evaluation of each of the projects for each conditional attribute. Employees who were present throughout the equipment upgrade project and played an active role, whether as user, trainer, supervisor or superintendent, qualified as respondents. Their participation in our study was voluntary. None of these participants was non-responsive. The research team conducted the interviews on company premises (at the mine).

Each project was evaluated on a performance scale according to a decisional attribute (column D in Table 1), meaning in terms of a given performance indicator. Three productivity performance indicators were examined (cost per meter drilled ${ }^{2}$, cost per hour of use, availability ratio) and one OHS performance indicator (accident rate) was examined. In addition to being recognized in the mining sector [7] [14]-[18], this choice of indicators met with the approval of the participating company. The performance indicators were measured over a period of 12 months to minimize bias due to seasonal variability, particularly the effect of summer heat on OHS [19]. Each project was compared to the equipment group in use over the 12-month period prior to the innovation project. Two precious studies measured the projects performance (see [20] for productivity and [21] for OHS.) Based on the results of these studies, we constructed scales for each of the performance indicators used in the present study, as shown below in Table 2.

Once the set of projects was evaluated in terms of each of the conditional attributes (contextual factors) and decisional attributes (performance indicators), it became possible to extract decision rules from the completed decision table. To achieve this, we used the program jMAF, which is a specialized software used for the calculation of dominance relationships, obtained from the Laboratory of Intelligent Decision Support Systems (LIDSS) at the Institute of Computing Science at Poznan University of Technology [22].

\section{Description of the Projects under Study}

The 10 projects that were examined in the course of our research are listed in Table 3 and described below.

Project 1, carried out in 2010, consisted of introducing a semi-automated bolting machine, which brought a major change to the actions of the equipment operator, who now remains seated in a closed, air-conditioned cabin from which he guides the devices using a hand-operated controller. This machine replaced conventional bolters that required the operator to handle and position the screens while standing on a platform reached by steps. We compared the performance of the new equipment with that of two reference groups, 1 and 1.5, using respectively seven and two vehicles of the old type.

Table 2. Scoring of the four performance indicators (decisional attributes).

\begin{tabular}{clll}
\hline & Cost per meter drilled & & Cost per hour of use \\
\hline Score & Improvement (\%) & Score & Improvement (\%) \\
$\mathbf{1}$ & None $(<0)$ & 1 & Low $(0-25)$ \\
$\mathbf{2}$ & Low $(0-25)$ & 2 & Medium $(25-50)$ \\
$\mathbf{3}$ & Medium $(25-50)$ & 3 & High $(>50)$ \\
$\mathbf{4}$ & High $(>50)$ & & \\
$\mathbf{3}$ & Availability & & Accident rate \\
$\mathbf{1}$ & Improvement (\%) & Score & Improvement (\%) \\
$\mathbf{2}$ & None $<0$ & 1 & Significant deterioration $(>50)$ \\
$\mathbf{3}$ & Low $(0-3)$ & 2 & Slight deterioration $(0-50)$ \\
$\mathbf{4}$ & Medium $(3-6)$ & 3 & Status quo (0) \\
& High $(>6)$ & 4 & Slight improvement $(0$ - 50) \\
\hline
\end{tabular}

\footnotetext{
${ }^{2}$ This indicator was used only for projects involving bolters and drillers, namely 1, 1.5, 2 and 3.
} 
Table 3. Ten mining equipment-upgrading projects.

\begin{tabular}{cccc}
\hline Project & Type of equipment & $\begin{array}{c}\text { Number of innovative } \\
\text { group vehicles }\end{array}$ & $\begin{array}{c}\text { Number of reference } \\
\text { group vehicles }\end{array}$ \\
\hline $\mathbf{1}$ & Bolter/semi-automated & 1 & 7 \\
$\mathbf{1 . 5}$ & Bolter/semi-automated & 1 & 2 \\
$\mathbf{2}$ & Bolter/new generation & 2 & 2 \\
$\mathbf{3}$ & Long-hole drill/new generation & 1 & 1 \\
$\mathbf{4}$ & 30-ton trucks versus 50-ton & 3 & 3 \\
$\mathbf{5}$ & 50-ton trucks versus 30-ton & 2 & 6 \\
$\mathbf{6}$ & LHD/new generation & 2 & 4 \\
$\mathbf{7}$ & LHD/cab + air conditioning & 6 & 9 \\
$\mathbf{8}$ & Supervisor tractor vehicles & 11 & 4 \\
$\mathbf{9}$ & Supervisor tractor vehicles & 9 & 8 \\
\hline $\mathbf{1 0}$ & Scissor lift/new generation & 2 & \\
\hline
\end{tabular}

Project 2 corresponds to the arrival in 2009 of two new-generation bolters equipped with platform lifts. The innovation consists of design improvements intended to decrease worker physical effort and fatigue. The reference group used two bolters of the same model but acquired 12 years earlier. Project 3, carried out in 2010, consisted of introducing a flexible electro-hydraulic long-hole drilling rig. This device was compared with a long-hole driller designed 20 years earlier.

Project 4 corresponds to the arrival of three 30-ton trucks in 2010, to replace part of the fleet of 1050 -ton trucks that had not met expectations in terms of productivity. The introduction of two of these 50-ton trucks in 2005 corresponds to project 5. These were compared with three older 30-ton trucks.

Project 6 corresponds to the arrival of two new 8-yard load-haul-dump (LHD) in 2009. These were needed to respond to the increasing productivity of the mine. Since the model in use at that point was no longer being manufactured, the company had to choose a new model and opted for one that has a new cabin design allowing easier access, better visibility, greater effectiveness of the air-conditioning system and a reduction in noise level. Project 7 corresponds to the introduction of six new LHD in 2007. The distinctive element of these machines is that they were the first closed-cabin air-conditioned vehicles purchased by the company.

Project 8, also carried out in 2010, corresponds to the arrival of 11 new tractor-like mining vehicles for underground transport of supervisors. Minor modifications distinguish these tractors from the reference group. Project 9 corresponds to the introduction of nine new tractor vehicles for supervisors in 2008. The reference group vehicles have significantly lower hauling capacity (kg of load and number of persons) and power. Finally, project 10 corresponds to the arrival of two new scissor-lifts in 2010. Certain technical improvements such as side-openings and greater speed motivated their choice.

\section{Results}

The rules presented in this section allowed approximations based on the listed projects. The quality of these approximations was $90 \%$, meaning that the rules explained correctly $90 \%$ of the project results in terms of the performance indicators studied.

\subsection{Key Factors Determining Improvements in Productivity}

The rules associated with cost per meter drilled are shown in Table 4. Three key attributes were identified for this performance indicator: acceptance of the new equipment by the operators, the skill required for the use of the equipment, and the degree of standardisation of the new relative to the old equipment. According to rule 1, to qualify as a major improvement (a decisional attribute score of at least 4), the project needed an operator acceptance rating of at least 5 (all operators accepted and adopted the new equipment). If the acceptance rating 
was no greater than 3 (about $50 \%$ of the users accepted and adopted the equipment), the project brought at best a slight improvement (Dec $\leq 2)$ in terms of this indicator of productivity. Likewise for skill and standardisation. Rules 3 and 5 inform us that a major improvement corresponded to respectively no special skill requirement (skill requirement rating $\geq 5$ ) or a standardisation rating of at least 3 . Rules 4 and 6 specify conversely that a skill requirement rating of 2 or less and a standardization rating of 1 meant that the improvement obtained in terms of cost per meter drilled was slight at best.

The rules for cost per hour of use are shown in Table 5. A single rule (rule 1) made it possible to determine a great improvement (Dec $\geq 3$ ) in terms of this performance indicator: a workspace quality rating of 5 must be obtained (excellent in all respects). This rule allowed us to explain the performance of four of the projects examined in this study. Rule 2, which was relevant in five projects, indicates that to obtain at least a moderate improvement (Dec $\geq 2$ ) in cost per hour of use, the project had to satisfy two conditions: a skill requirement rating of 4 (required skill is acquired easily with a bit of practice) and a rating of at least 5 for user involvement (active participation leading to rapid optimization of the new equipment use). Rules 3 and 4 identify respectively low acceptability and poor quality of field of vision as factors explaining the low improvement of this indicator. Finally, rule 5, which explains the results of five projects, informs us that a skill requirement rating of 4 or less leads at best to a moderate improvement.

The rules for identifying the key factors that determine the availability indicator are shown in Table 6. Rules 3, 4 and 9 explained the greatest number of results. Rule 3, which explained the results of six projects, specifies that a project that does not impose any special skill requirement led to at least a moderate improvement (Dec $\geq 3$ ) in terms of this performance indicator. According to rule 4, this performance level could also be reached when the standardisation rating for the new equipment was at least 4 (slight difference, one or two minor modifications intended to improve task execution). This rule was relevant to the results of five projects. Rule 9, also relevant to five projects, specifies that a rating no higher than 4 for user involvement (active participation but not leading rapidly to optimal use of the new equipment), led at best to a moderate improvement based on this indicator. It should be noted that low acceptability to the operators again led to no gain in productivity (rule 5), while a skill requirement found high or difficult to meet led at best to a slight improvement (rule 7).

Table 4. Key factors determining the performance indicator cost per meter drilled.

\begin{tabular}{ccc}
\hline Rule & Decision $^{\mathbf{a}}$ & Condition $^{\mathbf{b}}$ \\
$\mathbf{1}$ & $\geq 4$ & Acceptance $\geq 5$ \\
$\mathbf{2}$ & $\leq 2$ & Acceptance $\leq 3$ \\
$\mathbf{3}$ & $\geq 4$ & Skill $\geq 5$ \\
$\mathbf{4}$ & $\leq 2$ & Skill $\leq 2$ \\
$\mathbf{5}$ & $\geq 4$ & Standard $\geq 3$ \\
$\mathbf{6}$ & $\leq 2$ & Standard $\leq 1$ \\
\hline
\end{tabular}

a. See Table 2 for definitions of the decisional attributes and their scoring. b. See Appendix for definitions of the conditional attributes and their rating scale.

Table 5. Key factors determining the performance indicator cost per hour of use.

\begin{tabular}{cccc}
\hline Rule & Decision $^{\mathbf{a}}$ & Condition $^{\mathbf{b}}$ & Condition 2 \\
\hline $\mathbf{1}$ & $\operatorname{Dec} \geq 3$ & Workspace $\geq 5$ & Involvement $\geq 5$ \\
$\mathbf{2}$ & $\operatorname{Dec} \geq 2$ & Skill $\geq 4$ & \\
$\mathbf{3}$ & $\operatorname{Dec} \leq 1$ & Acceptance $\leq 2$ & \\
$\mathbf{4}$ & $\operatorname{Dec} \leq 1$ & Vision $\leq 2$ & \\
$\mathbf{5}$ & $\operatorname{Dec} \leq 2$ & Skill $\leq 4$ & \\
\hline
\end{tabular}

a. See Table 2 for definitions of the decisional attributes and their scoring. b. See Appendix for definitions of the conditional attributes and their rating scale. 


\subsection{Key Factors Determining Improvement of the Accident Rate}

Table 7 shows the rules obtained for the indicator frequency of accidents. Rule 4 is the most relevant, being applicable to four projects. The accident rate decreased slightly when $50 \%$ of the users of the equipment had at least 6.12 years of experience in the mine (Dec $\geq 2$ ). Rules 6, 7, 8 and 10 indicate that a project that did not receive a rating of 5 for seat quality led at best to maintenance of the status quo for this OHS indicator (sometimes bundled with another attribute), while rules 2 and 3 specify that a seat quality rating of 5 bundled with skill requirement and acceptance scores of respectively 5 and 4 led to the status quo in the worst case.

\section{Discussion}

The use of the decision-aid tool enabled us to achieve our initial goal, which was to identify the factors that are the most relevant for a successful introduction of innovative mining equipment. Among the three indicators of productivity, our analysis points to operator acceptance of the new equipment, the skill required to use the equipment and the degree of standardisation of the new equipment relative to the old as the most relevant and

Table 6. Key factors determining the performance indicator availability.

\begin{tabular}{|c|c|c|c|}
\hline Rule & Decision $^{a}$ & Condition $1^{b}$ & Condition 2 \\
\hline 1 & $\operatorname{Dec} \geq 4$ & Seat $\geq 5$ & Workspace $\geq 5$ \\
\hline 2 & $\operatorname{Dec} \geq 4$ & Involvement $\geq 5$ & On task $\geq 1.58$ \\
\hline 3 & $\operatorname{Dec} \geq 3$ & Skill $\geq 5$ & \\
\hline 4 & $\operatorname{Dec} \geq 3$ & Standard $\geq 4$ & \\
\hline 5 & $\operatorname{Dec} \leq 1$ & Acceptance $\leq 2$ & \\
\hline 6 & $\operatorname{Dec} \leq 1$ & Vision $\leq 2$ & \\
\hline 7 & $\operatorname{Dec} \leq 2$ & Skill $\leq 2$ & \\
\hline 8 & $\operatorname{Dec} \leq 2$ & Involvement $\leq 3$ & \\
\hline 9 & $\operatorname{Dec} \leq 3$ & Involvement $\leq 4$ & \\
\hline 10 & $\operatorname{Dec} \leq 3$ & Seat $\leq 4$ & Age $\leq 35.0$ \\
\hline
\end{tabular}

a. See Table 2 for definitions of the decisional attributes and their scoring. b. See Appendix for definitions of the conditional attributes and their rating scale.

Table 7. Key factors determining the performance indicator accident rate.

\begin{tabular}{|c|c|c|c|}
\hline Rule & Decision $^{a}$ & Condition $1^{\mathrm{b}}$ & Condition 2 \\
\hline 1 & $\operatorname{Dec} \geq 5$ & On task $\geq 4.3$ & \\
\hline 2 & $\operatorname{Dec} \geq 4$ & Skill $\geq 5$ & Seat $\geq 5$ \\
\hline 3 & $\operatorname{Dec} \geq 3$ & Acceptance $\geq 4$ & Seat $\geq 5$ \\
\hline 4 & $\operatorname{Dec} \geq 2$ & On job $\geq 6.12$ & \\
\hline 5 & $\operatorname{Dec} \leq 1$ & Acceptance $\leq 2$ & \\
\hline 6 & $\operatorname{Dec} \leq 1$ & Seat $\leq 2$ & Workspace $\leq 4$ \\
\hline 7 & $\operatorname{Dec} \leq 1$ & Seat $\leq 4$ & Age $\leq 35.0$ \\
\hline 8 & $\operatorname{Dec} \leq 2$ & Seat $\leq 2$ & \\
\hline 9 & $\operatorname{Dec} \leq 3$ & Vision $\leq 2$ & \\
\hline 10 & $\operatorname{Dec} \leq 3$ & Seat $\leq 4$ & On job $\leq 5.73$ \\
\hline
\end{tabular}

a. See Table 2 for definitions of the decisional attributes and their scoring. b. See Appendix for definitions of the conditional attributes and their rating scale. 
recurrent factors involved in determining the impact of the project. For OHS measured in terms of accident rate, seat quality and years of worker experience were the conditional attributes that appeared most often to explain project impact. By adopting an overall systemic view, two factors were identified as relevant to each of the productivity performance indicators studied, namely operator acceptance of the new equipment and the skill required to use it properly.

The 12-month period over which our data were gathered provided some internal validation of our study. Seasonal bias, in particular due to summer temperatures, was thus avoided [19]. Our results are nevertheless limited to the study of a single underground mine in Quebec. External validation of the study, that is, generalizing the results to mines elsewhere, would require future research in such mines. Individual companies could adopt our approach to identify the key factors that were involved in the successful equipment upgrades in their respective mines.

It should be noted that we took into consideration only operators who were employees of the mine. We therefore did not consider accidents that occurred in association with equipment maintenance or those that involved workers employed by mining subcontractor companies.

The lack of certain types of data constitutes another limitation of our study. As is often the case, some information appears to have disappeared over time or otherwise became unavailable. This was the case notably for employee age and experience and OHS performance in the case of the two supervisor tractor vehicle projects. These vehicles were not assigned to specific employees and this information was impossible to gather. Likewise, the performance in project 5 in terms of equipment availability was not known with any certainty since complete records for these years were no longer available.

In spite of a thorough initial review of the literature intended to identify all factors likely to have an influence, some attributes were not accessible to study. This was the case for behavioural adaptation of workers in response to the arrival of the new equipment. As the theory of risk homeostasis suggests [23]-[25], an individual tends to devote less effort to health and safety as the perceived risk decreases in his judgment. The opposite is also true. A process of regulation is supposedly at work, to allow the individual to function at a level of risk perceived as constant. A study has noted this in the mining context [26], and suggests that introducing new technology can lead to operator behaviours that are less safe. However, we were not able to evaluate the entire group of equipment users and thereby report any precise and reliable results regarding this perspective on the research question.

Our results are consistent with previous conclusions regarding the implications of the current trend in mining equipment towards increasing power, complexity and sophistication [5] [27]. To provide the promised economic gain and increased efficiency at minimal risk, these machines require operators with superior skills. Our findings confirm this, as much for productivity as for OHS. We observed that when the new equipment did not require any special skill, improvements in both domains were significant. When superior skills were required, improvements in productivity were smaller.

The same observation applied when level of acceptance of the new equipment by the operators was low. Operator slowness to feel at ease with and adopt the equipment led to unsatisfactory results in terms of productivity and OHS in the projects that we studied. This confirms previous findings that supervisors and managers need to develop skills in the management of change [26].

We also noted an interesting combined effect of seat quality and workspace. This combination was relevant not only to OHS performance (rule 6 in Table 7) but also to productivity in terms of the availability indicator (Rule 1 in Table 6). Although the literature does contain discussion of problems associated with seat comfort [28] and cabin design [29] in mining vehicles, our results provide additional information by showing that a major improvement in performance was obtained when both of these attributes received the highest quality rating, both individually (Rule 1 in Table 5) and in combination. Since this level of quality was essential for obtaining the improvement, the specific seat and workspace characteristics that earn such ratings should be identified in future research.

The arrival of new semi-automated equipment since the turn of the millennium has allowed a reduction or elimination of certain physically demanding tasks. Project 1 in our sample is representative of this evolution. The operator no longer has to handle the screens while standing on a platform to execute the bolting task. Bolting is now performed in a seated position inside a closed, air-conditioned cabin using a hand control. The two mechanical arms of the machine handle the screens and hold them in place during bolting. This abrupt change in the mode of execution of the task was beneficial in terms of OHS. However, its impact on productivity was quite 
different [20]. The rules identified confirmed the difficulty of obtaining even moderate improvements as soon as one or more modifications change even part of the mode of execution of the task. This finding has support in the form of a theory popularized long ago in the scientific literature [30], according to which technologies follow an S-shaped lifecycle. A new technology requires some time before it can even reach, let alone surpass, the level of performance of an existing matured technology. Once the new technology is understood, the performance achieved using it improves quickly and surpasses the performance of the old system, which had reached its limits. When this occurs, the old technology has become out-dated. According to this theory, the users of the new technology thus need time to and concretize gains. Our results support very well this theory. Although we found that the larger the modification involved the less likely was an immediate gain in productivity, it remains to be seen whether or not the disruptive new technologies will lead ultimately to performances that are in fact superior.

The age of the equipment operator was not found to be a factor in our study, in contrast with previous findings [7]. However, operator experience did play a key role, especially in OHS performance. Experience with the particular task and experience as an employee in the mine both contributed to improving the accident rate. Other studies of mining have reached similar conclusions, in particular with regard to worker experience. In a study of accidents involving mining vehicles in the USA from 1995 to 2004, the workers involved had less than five years of experience in over $50 \%$ of cases [31]. In our study, the critical threshold for the contribution of the experience attribute to the accident rate ranged from four to six years.

\section{Conclusion}

The main contribution of this article is precise identification of the key factors that allowed the introduction of new equipment to bring the desired improvements in productivity and OHS in the participating mine. Among the approximately 20 contextual factors that were examined, skill requirement and equipment acceptance by operators were identified as the most relevant to the studied performance indicators as a whole. In addition to these factors, seat quality and operator experience were found relevant to explaining OHS performance, while degree of standardisation of the new equipment relative to the old also explained some of the impact of its introduction on productivity. Identifying these key factors and their critical threshold values will help the directors of the participating mine take both productivity and OHS into consideration in their management and evaluation of future introduction of innovative equipment.

\section{References}

[1] Bartos, P. (2007) Is Mining a High-Tech Industry? Investigations IntoInnovation and Productivity Advance. Resources Policy, 32, 149-158. http://dx.doi.org/10.1016/j.resourpol.2007.07.001

[2] Vallières, M. (1989) Mines and Men: History of the Mineral Industry from Quebec_-Des Mines et des Hommes: Histoire de l’Industrie Minérale Québécoise. Les Publications du Québec, Québec.

[3] Groupe de Travail sur le Permis Social (2010) Report on the Performance of the Mining Sector 1998-2009—Rapport sur la Performance du Secteur Minier 1998-2009. Conférence des ministres de l'énergie et des mines de 2010.

[4] Upstill, G. and Hall, P. (2006) Innovation in the Minerals Industry: Australia in a Global Context. Resources Policy, 31, 137-145. http://dx.doi.org/10.1016/j.resourpol.2006.12.002

[5] Dhillon, B.S. (2010) Mine Safety: A Modern Approach. Springer, London. http://dx.doi.org/10.1007/978-1-84996-115-8

[6] CEMI (Center for Excellence in Mining Innovation) (2013) Mine Automation-A Vision of Our Future. Ultra-Deep Mining Workshop, Sudbury, 12-13 June 2013.

[7] Ural, S. and Demirkol, S. (2008) Evaluation of Occupational Safety and Health in Surfaces Mines. Safety Science, 46, 1016-1024. http://dx.doi.org/10.1016/j.ssci.2007.11.010

[8] Kecojevic, V., Komljenovic, D., Groves, W. and Radomsky, M. (2007) An Analysis of Equipment-Related Fatal Accidents in U.S. Mining Operations: 1995-2005. Safety Science, 45, 864-874. http://dx.doi.org/10.1016/j.ssci.2006.08.024

[9] Smets, M., Eger, T.R. and Grenier, S. (2010) Whole-Body Vibration Experienced by Haulage Truck Operators in Surface Mining Operations: A Comparison of Various Analysis Methods Utilized in the Prediction of Health Risks. Applied Ergonomics, 41, 763-770. http://dx.doi.org/10.1016/j.apergo.2010.01.002

[10] Ruff, T., Coleman, P. and Martini, L. (2011) Machine-Related Injuries in the US Mining Industry and Priorities for 
Safety Research. International Journal of Injury Control and Safety Promotion, 18, 11-20. http://dx.doi.org/10.1080/17457300.2010.487154

[11] Trudel, B., Nadeau, S., Zaras, K. and Deschamps, I. (2012) The Impact of Technological Innovation on Productivity and OHS Performance in Mining. Proceedings of the 2012 Conference of the Nordic Ergonomics Society (NES2012), Stockholm, 19-22 August 2012, 90.

[12] Greco, S., Matarazzo, B. and Slowinski, R. (2001) Rough Sets Theory for Multi-Criteria Decision Analysis. European Journal of Operational Research, 129, 1-47. http://dx.doi.org/10.1016/S0377-2217(00)00167-3

[13] Zaras, K. (2004) Rough Approximation of a Preference Relation by a Multi-Attribute Dominance for Deterministic, Stochastic and Fuzzy Decision Problems. European Journal of Operational Research, 159, 196-206. http://dx.doi.org/10.1016/S0377-2217(03)00391-6

[14] Chadwick, J. (2008) Moving Ore Efficiently. International Mining, 38-46.

[15] Horberry, T., Burgess-Limerick, R. and Steiner, L. (2011) Human Factors for the Design, Operation, and Maintenance of Mining Equipment. CRC Press, New York.

[16] Karmis, M. (2001) Mine Health and Safety Management. Society for Mining, Metallurgy, and Exploration, Inc., Littleton.

[17] Coleman, P.J. and Kerkering, J.C. (2007) Measuring Mining Safety with Injury Statistics: Lost Workdays as Indicators of Risk. Journal of Safety Research, 38, 523-533. http://dx.doi.org/10.1016/j.jsr.2007.06.005

[18] MSHA (Mine Safety and Health Administration) (2013) Mine Injury and Worktime, Quarterly. Yearly Reports, January-June 2013 (Preliminary). http://www.msha.gov/Stats/Part50/WQ/MasterFiles/MIWQ\%20Master_20132.pdf

[19] Dessureault, P.C. and Doucet, M. (2003) Evaluation of the Thermal Constraint Indicators in Deep Mining- Évaluationdes Indices de Contrainte Thermique en Mines Profondes. R-350, Institut de Recherche Robert-Sauvé en Santé et en Sécurité du Travail, Montréal.

[20] Trudel, B., Nadeau, S., Zaras, K. and Deschamps, I. (2014) Introduction of Innovative Equipment in Mining: Impact on Productivity. American Journal of Industrial and Business Management, 4, 31-39. http://dx.doi.org/10.4236/ajibm.2014.41006

[21] Trudel, B., Nadeau, S., Zaras, K. and Deschamps, I. (2014) Introduction of Innovative Equipment in Mining: Impact on OHS. Open Journal of Safety Science and Technology, 4, 49-58. http://dx.doi.org/10.4236/ojsst.2014.41007

[22] Laboratory of Intelligent Decision Support Systems (LIDSS) (2014) Software jMAF. Institute of Computing Science, Poznan University of Technology. http://idss.cs.put.poznan.pl/site/139.html

[23] Wilde, G.J.S. (1982) The Theory of Risk Homeostasis: Implications for Safety and Health. Risk Analysis, 2, $209-225$. http://dx.doi.org/10.1111/j.1539-6924.1982.tb01384.x

[24] Wilde, G.J.S. (1988) Risk Homeostasis Theory and Traffic Accidents: Propositions, Deductions and Discussion of Dissension in Recent Reactions. Ergonomics, 31, 441-468. http://dx.doi.org/10.1080/00140138808966691

[25] Wilde, G.J.S. (1998) Risk Homeostasis Theory: An Overview. Injury Prevention: Journal of the International Society for Child and Adolescent Injury Prevention, 4, 89-91. http://dx.doi.org/10.1136/ip.4.2.89

[26] Lynas, D. and Horberry, T. (2011) Human Factor Issues with Automated Mining Equipment. The Ergonomics Open Journal, 4, 74-80. http://dx.doi.org/10.2174/1875934301104010074

[27] Dhillon, B.S. (2009) Mining Equipment Safety: A Review, Analysis Methods and Improvement Strategies. International Journal of Mining, Reclamation and Environment, 23, 168-179. http://dx.doi.org/10.1080/17480930902916239

[28] Eger, T., Stevenson, J., Boileau, P.-E. and Salmoni, A., Vibration Research Group (2008) Predictions of Health Risks Associated with the Operation of Load-Haul-Dump Mining Vehicles: Part 2-Evaluation of Operator Driving Postures and Associated Postural Loading. International Journal of Industrial Ergonomics, 38, 801-815. http://dx.doi.org/10.1016/j.ergon.2007.09.003

[29] Roque, N., Nadeau, S. and Badri, A. (2014) Preliminary Ergonomics of a Bolting Machine and a Drill Used in Underground Mining. Proceedings of the Gesellschaftfür Arbeitswissenschaft (GFA2014), Munich, 12-14 March 2014, 339341.

[30] Christensen, M. (1992) Exploring the Limits of the Technology S-Curve, Part I: Components Technologies. Production and Operations Management, 1, 334-357. http://dx.doi.org/10.1111/j.1937-5956.1992.tb00001.x

[31] Groves, W.A., Kecojevic, V.J. and Komljenovic, D. (2007) Analysis of Fatalities and Injuries Involving Mining Equipment. Journal of Safety Research, 38, 461-470. http://dx.doi.org/10.1016/j.jsr.2007.03.011 


\section{Appendix-Conditions under Which the Projects Were Carried out}

\begin{tabular}{|c|c|}
\hline Rating & Conditional attribute and definitions \\
\hline \multicolumn{2}{|r|}{ Acceptance $=$ acceptability of the equipment to the operators } \\
\hline 1 & No user previously experienced with the task accepted or adopted the new equipment. \\
\hline 2 & About $25 \%$ of the users accepted and adopted the equipment. The remaining $75 \%$ switched back to the old equipment. \\
\hline 3 & About $50 \%$ of the users accepted and adopted the equipment. The remaining $50 \%$ switched back to the old equipment. \\
\hline 4 & About $75 \%$ of the users accepted and adopted the equipment. The remaining $25 \%$ switched back to the old equipment. \\
\hline 5 & All users previously experienced with the task accepted or adopted the new equipment \\
\hline \multicolumn{2}{|r|}{ Skill = requirement for additional (new) skill } \\
\hline 1 & The skill required to operate the equipment is difficult to acquire. \\
\hline 2 & The skill required is considerable, is acquired on the long term with practice. \\
\hline 3 & The skill requirement is moderate, is met on the medium term with practice. \\
\hline 4 & The skill required is minimal, is acquired easily with a bit of practice. \\
\hline 5 & No special skill is required. \\
\hline \multicolumn{2}{|r|}{ Standard = degree of standardisation of the new equipment relative to the old } \\
\hline 1 & The new equipment is not comparable (the mode of task execution is disruptive). \\
\hline 2 & Differs markedly (one or more major modifications transform the task in part). \\
\hline 3 & Moderate difference (various minor modifications intended to improve task performance). \\
\hline 4 & Slight difference (one or two modifications intended to improve task performance). \\
\hline 5 & Practically no change (the modifications are not apparent in the execution of the task). \\
\hline \multicolumn{2}{|r|}{ Workspace $=$ quality (comfort) of the space surrounding the operator } \\
\hline 1 & Poor, several aspects (unspecified) need improvement. \\
\hline 2 & Average, at least two aspects (unspecified) need improvement. \\
\hline 3 & Acceptable overall. \\
\hline 4 & Very good, except for one aspect that could be improved. \\
\hline 5 & Excellent in all aspects. \\
\hline \multicolumn{2}{|r|}{ Involvement of the operators in the equipment implementation process } \\
\hline 1 & No involvement (indifference to the success of the equipment introduction). \\
\hline 2 & Passive participation, operator somewhat responsive. \\
\hline 3 & Whimsically passive or active involvement. \\
\hline 4 & Active involvement not leading to rapid optimisation of the use of the new equipment. \\
\hline 5 & Involvement leading to rapid optimisation of the use of the new equipment. \\
\hline \multicolumn{2}{|r|}{ Vision = Quality of the field of vision } \\
\hline 1 & Poor, hindered by one or two aspects making equipment operation difficult or dangerous. \\
\hline 2 & Average, one or two aspects occasionally making operation difficult or dangerous. \\
\hline 3 & Acceptable overall. \\
\hline 4 & Very good, except for one aspect that could be improved. \\
\hline
\end{tabular}




\section{Continued}

5

1

2

3

4

5

1

2

3

4

5
Excellent in all aspects

\section{Seat $=$ Quality of the seat}

Poor (uncomfortable).

Average.

Acceptable, with one or two problems.

Good, no real problem.

Very comfortable.

Service $=$ Involvement of the equipment manufacturer in the implementation process

Poor follow-up during the breaking-in period.

Minimally adequate follow-up during the breaking in period.

Satisfactory follow-up during the breaking in period.

Entirely satisfactory follow-up during the breaking in period.

On task = years of experience with the task associated with the equipment

Corresponding to the median for all users of the equipment.

On job = years of experience as a worker in this mine

Corresponding to the median for all users of the equipment.

Age $=$ age of worker when the new equipment arrived

Corresponding to the mean for all users of the equipment. 